BMJ Open Sport \& Exercise Medicine

\title{
Recreational soccer as sport medicine for middle-aged and older adults: a systematic review
}

\author{
Hao Luo,,$^{1,2,3}$ Robert U Newton, $, 2,3,4,5$ Fadi Ma'ayah, ${ }^{3}$ Daniel A Galvão,, \\ Dennis R Taaffe Th, $^{2,3}$
}

To cite: Luo H, Newton RU, Ma'ayah F, et al. Recreational soccer as sport medicine for middle-aged and older adults: a systematic review. BMJ Open Sport \& Exercise Medicine 2018;4:e000336. doi:10.1136/ bmjsem-2017-000336

- Additional material is published online only. To view please visit the journal online (http://dx.doi.org/10.1136/10. 1136/bmjsem-2017-000336).

Accepted 25 July 2018

Check for updates

C) Author(s) (or their employer(s)) 2018. Re-use permitted under CC BY-NC. No commercial re-use. See rights and permissions. Published by BMJ.

${ }^{1}$ Department of Exercise and Health Sciences, Guangdong Vocational Institute of Sport, Guangzhou, Guangdong, China ${ }^{2}$ Exercise Medicine Research Institute, Edith Cowan University, Joondalup, Western Australia, Australia

${ }^{3}$ School of Medical and Health Sciences, Edith Cowan University, Joondalup, Western Australia, Australia

${ }^{4}$ University of Queensland Centre for Clinical Research, University of Queensland, Brisbane,

Queensland, Australia

${ }^{5}$ Institute of Human

Performance, The University of Hong Kong, Hong Kong, China ${ }^{6}$ School of Human Movement and Nutrition Sciences, University of Queensland, Brisbane, Queensland, Australia

Correspondence to Dr Dennis R Taaffe; d.taaffe@ ecu.edu.au

\section{ABSTRACT}

Background Strategies to prevent or attenuate the age-related decline in physical and physiological function and reduce chronic disease risk factors are of clinical importance.

Objective To examine the health benefits of recreational soccer in middle-aged and older adults.

Design Systematic review in accordance with the Preferred Reporting Items for Systematic Reviews and Meta-Analyses guidelines.

Data sources All available records up until 9 June 2017 in PubMed, Web of Science, SPORTDiscus, MEDLINE, Embase, CINAHL Plus, PsycINFO and Cochrane Library databases.

Eligibility criteria for selecting studies All randomised trials with or without a control group (randomised controlled trials or randomised uncontrolled trials) and non-randomised controlled trials that used recreational soccer, which includes small-sided soccer games, as the sole or principal intervention, and reported relevant effects in untrained/sedentary, healthy or unhealthy adults aged 40 years and above were included.

Results Five trials described in 13 articles were included, which scored 6-9 out of 12 points on the modified Delphi quality rating scale. The duration was from 12 to 52 weeks, with various frequencies, volumes and game formats performed both outdoors and indoors with men and women. The trials indicate that recreational soccer may result in improvement in cardiovascular function, body composition and functional ability, although no significant changes were observed in postural balance.

Conclusion Recreational soccer should be considered an alternative exercise modality for untrained, healthy or unhealthy middle-aged and older adults of both sexes to maintain an active lifestyle and mitigate a wide array of physical and physiological age-related changes.

\section{INTRODUCTION}

Human ageing is characterised by a progressive decline in physical and physiological function, ${ }^{1}$ and is a major risk factor for most non-communicable diseases. ${ }^{2}$ The occurrence of multiple clinical conditions is higher from mid-life to old age, including cancer, ${ }^{3}$ hypertension, ${ }^{45}$ sarcopaenia, ${ }^{6}$ osteoporosis ${ }^{78}$ and diabetes. ${ }^{9}$ Thus, preventive strategies
What is already known on this topic?

- Recreational soccer is a health promotion activity for a wide range of populations.

- Considerable health-related benefits are derived in both healthy and clinical populations.

- Participation in recreational soccer appears to be safe for older adults.

\section{What are the new findings?}

- Recreational soccer played with 3-7 people each side on an outdoor field or indoor court for 12-52 weeks results in significant positive adaptations in cardiorespiratory capacity, body composition, lower limb muscle function and strength in untrained, healthy and unhealthy middle-aged and older adults.

- Postural balance appears to be less responsive to change following recreational soccer training in this age group.

that can defer and/or prevent age-related declines in physical and physiological function and reduce chronic disease risk factors are of clinical importance.

It is well established that physical activity is an effective and low-cost approach to counter most age-related conditions with minimal side effects or risks ${ }^{10}$; however, inactivity generally increases with advancing age. ${ }^{11}$ Sport is recognised as a mechanism to promote an active lifestyle among the general public, and as suggested by Khan and colleagues ${ }^{12}$ sport participation can contribute to a healthier nation by increasing the physical activity level of the population. However, the efficacy of a given sport to improve public health will be dependent not only on the prevalence of and participation in the sport, but also on physical demands of the activity and the resulting health-derived benefits. ${ }^{13}$

Soccer has long been considered the world's number one sport. ${ }^{14}$ Over the last decade, recreational soccer (RS), characterised by fewer players per side and played on 
a smaller field than a standard competitive soccer game, and includes small-sided games, has emerged as a health promotion activity for various populations. Work to date indicates that RS positively motivates individuals and facilitates social interaction, which may enhance compliance and adherence to the activity and contribute to a physically active lifestyle, ${ }^{15}$ and has considerable health benefits in both healthy and clinical populations. ${ }^{16}$ In addition, RS has been shown to be superior to traditional exercise regimens (such as running) in enhancing postural balance, ${ }^{17}$ lower limb bone health, ${ }^{18}$ body composition ${ }^{19}$ and maximum oxygen uptake $\left(\mathrm{VO}_{2 \max }\right)^{20}$ in inactive, healthy and unhealthy adults. Moreover, RS has proven to be safer than competitive soccer games with a comparable injury risk $(<5 \%)$ to the low-impact activity (eg, endurance running), ${ }^{21}$ and the incidence of injury tends to be lower with older participants due to the reduction in movement speed as well as less impact and contact of players. ${ }^{22}$

Although a small but increasing number of papers regarding the training effects of RS in middle-aged and old-aged adults have been published in recent years, to the best of the authors' knowledge no systematic review is available focusing exclusively on the health-related effects of RS in untrained middle-aged and older adults. This is important as strategies to prevent the development of chronic disease in middle-aged and older adults, as well as improve health outcomes in those with chronic disease, are an important public health outcome and sport medicine may have a substantial role to play. Therefore, the purpose of the present systematic review was to examine the effects of RS training on health-related outcomes in middle-aged and older persons.

\section{METHODS}

This systematic review was conducted and reported in accordance with the recommendations in the Preferred Reporting Items for Systematic Reviews and Meta-Analyses $^{23}$ (see online supplementary file 1 ).

\section{Search strategy}

Electronic searching of all available records up until 9 June 2017 was undertaken in SPORTDiscus, MEDLINE, CINAHL Plus, PsycINFO, PubMed, Embase, Cochrane Library and Web of Science databases. Thesaurus terms and free-text terms were used either singly or in every possible combination. Thesaurus terms used were 'football' OR 'soccer'. Free-text terms used in combination with thesaurus terms were keywords for intervention ('recreational soccer' OR 'small-sided soccer' OR 'street soccer' OR 'walking soccer' OR 'small-volume soccer' OR 'indoor soccer' and the related terms) AND keywords for population ('untrained' OR 'patient*' OR 'premenopausal' OR 'postmenopausal' OR 'middle*aged' OR 'old*aged' and their synonyms) (see online supplementary file 2). No limitations were defined for the results during the search. In addition, author searches were performed for the influential authors Peter Krustrup, Jens
Bangso and Morten Bredsgaard Randers, who were the authors most published in the area of recreational football/soccer (ranked by Web of Science). The reference lists of relevant primary and secondary studies (review articles, executive summary and editorials) were checked to ensure further identification of eligible studies.

\section{Selection criteria}

To identify eligible articles, the titles and abstracts of identified records were first reviewed by HL to exclude irrelevant articles. Only peer-reviewed journal articles with full text and published in English were eligible for further review. Two review authors (HL and DRT) checked the eligibility of full-text articles independently based on the following inclusion criteria: (1) intervention-RS played for health and fun on an indoor or outdoor field was included (no limitations were imposed on such factors as duration, frequency, intensity or volume of the intervention programme); (2) population-untrained, healthy or unhealthy adults aged $40+$ years, both men and women, were included (older adults were classed as those aged 65 years and above, and there was no upper age limit for inclusion in the review); and (3) study design-randomised controlled trials (RCTs), randomised uncontrolled trials (RUTs) and non-randomised controlled trials (NRCTs) with RS as the sole or major intervention were included (interventions with more than one comparison group including control group were also accepted).

When differences occurred, a third review author (RUN) evaluated the article, and consensus among the three reviewers was achieved. Eligible articles were further examined to differentiate articles based on the same trials and subjects.

\section{Data extraction}

The characteristics of all included trials with regard to populations, intervention programme and outcomes were collected by using a pre-established data extraction form, which was pilot-tested by HL. Data extraction was performed independently by HL and DRT. Due to the numerous inconsistencies and ambiguities existing among included papers from the same trial regarding the characteristics of the participants, intervention programme and outcomes, a consensus agreement was sought and achieved among all review authors in cases of discrepancy on data extraction.

\section{Risk of bias assessment}

The risk of bias assessment of all included trials was performed by DRT and HL independently in accordance with a modified Delphi list. ${ }^{24}$ When consensus was not achieved for a trial, one of two review authors (FM or RUN) was employed for adjudication.

The Delphi list is a commonly used rating tool for methodological quality of RCTs for systematic review, which consists of nine rating items. ${ }^{24}$ Given the characteristics of the exercise intervention, two of the nine original items 


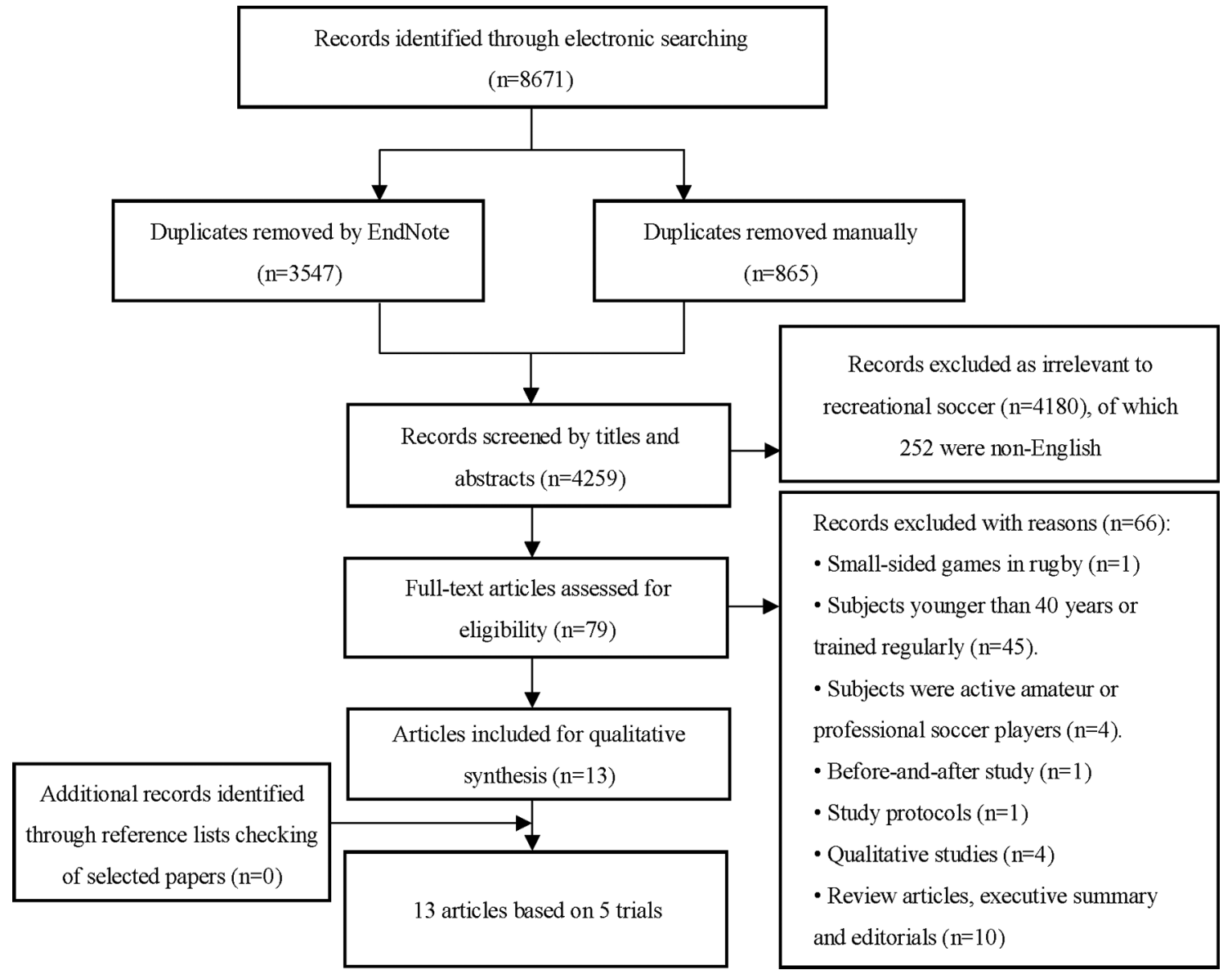

Figure 1 Flow diagram of study selection.

were removed, that is, blinded care provider and blinded patient, while another five items were added, that is, power calculation, between-group statistical comparison, exercise adherence, reporting dropouts and provision of supervised training ${ }^{25}$ (see online supplementary file 3 ).

Items were equally rated by 'yes', 'no' or 'not reported', in which 'yes' was counted for 1 point, while 'no' and 'not reported' equalled 0 point. Consequently, 0-12 points could be attained for any included articles, with a higher score indicating higher methodological trial quality. ${ }^{26}$

\section{RESULTS}

\section{Study selection}

The electronic search yielded 8671 records and the detailed search process is shown in figure 1. After duplicates were removed, a total of 4259 records were screened by titles and abstracts. After removing the articles out of scope (irrelevant to RS), the full text of 79 articles was further evaluated and 66 articles were removed based on relevant selection criteria. No extra records were identified after checking the reference lists of the eligible papers, review articles, executive summaries or editorials.

According to the inclusion criteria, 5 trials described in 13 articles ${ }^{227-38}$ were finally included, of which 4 independent trials were described in more than one paper. As all articles ${ }^{22} 27-38$ reported different health-related outcomes resulting from RS training, they were included in this systematic review.

\section{Risk of bias assessment}

The risk of bias assessment of the trials is presented in online supplementary file 4 . As four trials were described in more than one paper, the risk of bias was assessed based on the first published article. ${ }^{22} 27333638$ However, due to various disparities in trial description among papers from the same trial, the scores of the trials reported in the follow-up papers ${ }^{28-32} 343537$ are also listed. Scores of the included trials ${ }^{22} 27333638$ ranged from 6 to 9 points out of 12. The least scored criteria for the included articles were items 5 (blinded outcome assessor, 100\% absent), 2 (treatment allocation concealed, $92 \%$ absent) and 7 (intention-to-treat analysis, $85 \%$ absent), while the most scored criteria were items 3 (groups similar at baseline, $100 \%$ present), 4 (specific eligibility criteria, $100 \%$ present), $6 \mathrm{~b}$ (point estimates and measures of variability with values for each group, $100 \%$ present) and 9 (between-group statistical comparison, $100 \%$ present).

\section{Study characteristics}

The characteristics of included trials with regard to participants, intervention programme and outcomes are presented in tables 1-3, respectively. All papers were 
Table 1 Characteristics of the included articles: participants

\begin{tabular}{|c|c|c|c|c|c|}
\hline Author (year), country & Sex & $\begin{array}{l}\text { Subjects } \\
\text { randomised (n) }\end{array}$ & Mean $\pm S^{*}$ (age range) & $\begin{array}{l}\text { Subjects at post- } \\
\text { test (n) }\end{array}$ & Health status \\
\hline $\begin{array}{l}\text { Schmidt et al }{ }^{27} \text { (2013), } \\
\text { Denmark }^{\delta}\end{array}$ & $\mathbf{M}$ & $\begin{array}{l}27 \text { (STG: 14, CG: } \\
\text { 13) }\end{array}$ & $\begin{array}{l}49.8 \pm 1.7 \text { years }( \pm S E M) \\
\text { STG: } 50.6 \pm 7.1 \text { years }(n=12) \\
\text { CG: } 48.7 \pm 9.2 \text { years }(n=9)\end{array}$ & 18 (STG:10, CG:8) & T2D \\
\hline $\begin{array}{l}\text { Andersen et al }{ }^{28} \text { (2014), } \\
\text { Denmark }^{\delta}\end{array}$ & M & 21 (STG: 12, CG:9) & $\begin{array}{l}49.8 \pm 1.7 \text { years }( \pm \text { SEM }) \\
\text { STG: } 50.6 \pm 7.1 \text { years } \\
\text { CG: } 48.7 \pm 9.2 \text { years }\end{array}$ & 18 (STG:10, CG:8) & $\mathrm{T} 2 \mathrm{D}$ \\
\hline $\begin{array}{l}\text { Schmidt et al }{ }^{22} \text { (2014), } \\
\text { Denmark }^{\alpha}\end{array}$ & M & $\begin{array}{l}27 \text { (STG: 10, RTG: } \\
\text { 9, CG: 8) }\end{array}$ & $\begin{array}{l}68.2 \pm 3.2 \text { years }(65-75 \text { years) } \\
\text { STG: } 68.0 \pm 4.0 \text { years } \\
\text { RTG: } 69.1 \pm 3.1 \text { years } \\
\text { CG: } 67.4 \pm 2.7 \text { years }\end{array}$ & $\begin{array}{l}26 \text { (STG: 9, RTG: 9, } \\
\text { CG: 8) }\end{array}$ & Healthy \\
\hline $\begin{array}{l}\text { Andersen et al }{ }^{29} \text { (2014), } \\
\text { Denmark }^{\alpha}\end{array}$ & M & $\begin{array}{l}26 \text { (STG: 9, RTG: 9, } \\
\text { CG:8) }\end{array}$ & $\begin{array}{l}68.2 \pm 3.2 \text { years }(63-74 \text { years }) \\
\text { STG: } 68.0 \pm 4.0 \text { years } \\
\text { RTG: } 69.1 \pm 3.1 \text { years } \\
\text { CG: } 67.4 \pm 2.7 \text { years }\end{array}$ & $\begin{array}{l}26 \text { (STG: 9, RTG: 9, } \\
\text { CG: 8) }\end{array}$ & Healthy \\
\hline $\begin{array}{l}\text { Helge et al }{ }^{30} \text { (2014), } \\
\text { Denmark }^{\alpha}\end{array}$ & M & $\begin{array}{l}27 \text { (STG: 10, RTG: } \\
\text { 9, CG: 8) }\end{array}$ & $\begin{array}{l}68.2 \pm 3.2 \text { years }(65-75 \text { years) } \\
\text { STG: } 68.0 \pm 4.0 \text { years } \\
\text { RTG: } 69.1 \pm 3.1 \text { years } \\
\text { CG: } 67.4 \pm 2.7 \text { years }\end{array}$ & $\begin{array}{l}23 \text { (STG: 9, RTG: 8, } \\
\text { CG: 6) }\end{array}$ & Healthy \\
\hline $\begin{array}{l}\text { Andersen et al }{ }^{31} \text { (2016), } \\
\text { Denmark }^{\alpha}\end{array}$ & M & $\begin{array}{l}27 \text { (STG: 10, RTG: } \\
\text { 9, CG: 8) }\end{array}$ & $\begin{array}{l}68.1 \pm 2.1 \text { years }(63-74 \text { years }) \\
\text { STG: } 68.0 \pm 4.0 \text { years } \\
\text { RTG: } 69.1 \pm 3.1 \text { years } \\
\text { CG: } 67.4 \pm 2.7 \text { years }\end{array}$ & $\begin{array}{l}26 \text { (STG: 9, RTG: 9, } \\
\text { CG: 8) }\end{array}$ & Healthy \\
\hline $\begin{array}{l}\text { Sundstrup et al }{ }^{32} \text { (2016), } \\
\text { Denmark }^{\alpha}\end{array}$ & M & $\begin{array}{l}27 \text { (STG: 10, RTG: } \\
\text { 9, CG: 8) }\end{array}$ & $\begin{array}{l}68.2 \pm 3.2 \text { years } \\
\text { STG: } 68.0 \pm 4.0 \text { years } \\
\text { RTG: } 69.1 \pm 3.1 \text { years } \\
\text { CG: } 67.4 \pm 2.7 \text { years }\end{array}$ & $\begin{array}{l}25 \text { (STG: 9, RTG: 9, } \\
\text { CG: 7) }\end{array}$ & Healthy \\
\hline $\begin{array}{l}\text { Uth et }\left.a\right|^{33} \text { (2014), } \\
\text { Denmark }\end{array}$ & $\mathbf{M}$ & $\begin{array}{l}57 \text { (STG: 29, CG: } \\
28)\end{array}$ & $\begin{array}{l}\text { Average } 67 \text { years }(43-74 \\
\text { years) } \\
\text { STG: } 67.1 \pm 7.1 \text { years } \\
\text { CG: } 66.5 \pm 4.9 \text { years }\end{array}$ & $\begin{array}{l}49 \text { (STG: 26, CG: } \\
\text { 23) }\end{array}$ & $\mathrm{PCa}$ \\
\hline Uth et $\left.a\right|^{34}$ (2016), Denmark ${ }^{\gamma}$ & M & $\begin{array}{l}57 \text { (STG: 29, CG: } \\
\text { 28) }\end{array}$ & $\begin{array}{l}\text { STG: } 67.1 \pm 7.1 \text { years } \\
\text { CG: } 66.5 \pm 4.9 \text { years }\end{array}$ & $\begin{array}{l}41 \text { (STG: 21, CG: } \\
\text { 20) }\end{array}$ & $\mathrm{PCa}$ \\
\hline Uth et $a l^{35}$ (2016), Denmark ${ }^{\gamma}$ & M & $\begin{array}{l}57 \text { (STG: 29, CG: } \\
28)\end{array}$ & $\begin{array}{l}\text { Average } 67 \text { years } \\
\text { STG: } 67.1 \pm 7.1 \text { years } \\
\text { CG: } 66.5 \pm 4.9 \text { years }\end{array}$ & 48 (STG:26, CG: 22) & $\mathrm{PCa}$ \\
\hline $\begin{array}{l}\text { de Sousa et } a l^{36} \text { (2014), } \\
\text { Brazil }^{\beta}\end{array}$ & $\begin{array}{l}M \\
(n=17) \\
F \\
(n=27)\end{array}$ & $\begin{array}{l}44 \text { (DG: 22, SDG: } \\
22)\end{array}$ & $48-68$ years & $\begin{array}{l}34 \text { (DG: 15, SDG: } \\
\text { 19) }\end{array}$ & T2D \\
\hline $\begin{array}{l}\text { de Sousa et al }\left.\right|^{37} \text { (2017), } \\
\text { Brazil }^{\beta}\end{array}$ & $\begin{array}{l}M \\
(n=22) \\
F \\
(n=29)\end{array}$ & $\begin{array}{l}51 \text { (DG: 29, SDG: } \\
\text { 22) }\end{array}$ & $61.1 \pm 6.4$ years (48-68 years) & $\begin{array}{l}41 \text { (DG: 22, SDG: } \\
\text { 19) }\end{array}$ & T2D \\
\hline Reddy et $a^{38}$ (2017), UK & $\begin{array}{l}M \\
(n=17) \\
F(n=3)\end{array}$ & 20 (STG: 11, CG: 9) & $\begin{array}{l}50-65 \text { years } \\
\text { STG: } 61.1 \text { years } \\
\text { CG: } 58.3 \text { years }\end{array}$ & 20 (STG: 11, CG: 9) & NR \\
\hline
\end{tabular}

$\alpha, \beta, \gamma, \delta$ : studies based on the same trial.

As trial results are described in more than one paper, the bolded study represents the first published paper from a given exercise trial. ${ }^{*}$ Data are presented as mean $\pm S D$, unless otherwise stated.

CG, control group; DG, diet group; F, female; M, male; n, number of subjects; NR, not reported; PCa, prostate cancer; RTG, resistance training group; SDG, soccer+diet group; STG, soccer training group; T2D, type 2 diabetes.

published between 2013 and 2017, with the majority undertaken by a Danish group and the remainder by Brazilian and UK investigators.

\section{Participants}

Demographic data and health status

Two trials reported in three articles ${ }^{36-38}$ included both 
Table 2 Characteristics of included articles: interventions

\begin{tabular}{lllll}
\hline Author (year) & Design & Intervention programme & Intervention group & Comparison group(s) \\
\hline Schmidt et al $^{27}$ (2013) $^{\delta}$ & NRCT & 24 weeks; 2/week; 60 & ST: indoor; 4-6 players a & CG: maintain daily lifestyle. \\
& & min. & side; 5×10 min SSG; 1.2 & \\
& & & sessions/week completed; \\
& & & $82 \%$ HRmax.
\end{tabular}
$\begin{array}{lll}\text { Andersen et } a l^{28}(2014)^{\delta} & \text { NRCT } & \begin{array}{l}\text { As above (see Schmidt } \\ \text { et al, 2013). }\end{array}\end{array}$

$\begin{array}{lll}\text { Schmidt et } a l^{22}(2014)^{\alpha} & \text { RCT } & 12 \text { months; (month } \\ & \text { 1-4) 2/week, (month } \\ & 5-12) 3 / \text { week; } 1 \text { hour. }\end{array}$

Andersen et al ${ }^{29}(2014)^{\alpha} \quad$ RCT 16 weeks; 2/week; 1 hour.

\begin{tabular}{|c|c|c|}
\hline Helge et al ${ }^{30}(2014)^{\alpha}$ & RCT & $\begin{array}{l}\text { As above (see Schmidt } \\
\text { et al, 2014). }\end{array}$ \\
\hline Andersen et al ${ }^{31}(2016)^{\alpha}$ & $\mathrm{RCT}$ & $\begin{array}{l}\text { As above (see Schmidt } \\
\text { et al, 2014) }\end{array}$ \\
\hline $\begin{array}{l}\text { Sundstrup et } a l^{32} \\
(2016)^{\alpha}\end{array}$ & $\mathrm{RCT}$ & $\begin{array}{l}\text { As above (see Schmidt } \\
\text { et al, 2014). }\end{array}$ \\
\hline Uth et $a I^{33}(2014)^{\gamma}$ & RCT & $\begin{array}{l}12 \text { weeks; (weeks 1-8) } \\
\text { 2/week, (weeks 9-12) } \\
\text { 3/week; (weeks 1-4) } \\
45 \text { min, (weeks 5-12) } \\
1 \text { hour. }\end{array}$ \\
\hline
\end{tabular}

$\begin{array}{lll}\text { Uth et }\left.a\right|^{34}(2016)^{\gamma} & \text { RCT } & 32 \text { weeks; (weeks 1-8) } \\ & & \text { 2/week, (weeks 9-12) } \\ & & 3 / \text { week, (weeks 13-32) } \\ & \text { 2/week; (weeks 0-4) } \\ & 45 \text { min, (weeks 5-32) } 1 \\ & & \text { hour. } \\ & & \text { As above (see Uth et al, } \\ \text { Uth et a }{ }^{35}(2016)^{\gamma} & \text { RCT } & \text { 2014). }\end{array}$
2014).
As above (see Schmidt et al, 2014), but only played outdoors (4-6 players a side), $77.1 \%$ of all sessions completed with average intensity of $\sim 82 \%$ HRmax.

As above (see Schmidt et al, 2014), but only played outdoors with average intensity of $\sim 82 \%$ HRmax.

As above (see Schmidt et al, 2014).

As above (see Schmidt et al, 2014), but 4-5 players a side with average intensity of weeks $13-52$ was $1.5 \mathrm{~min}$. 82\% HRmax.

ST: outdoor/indoor; 5-7 players a side; supervised, (weeks 1-4) $2 \times 15 \mathrm{~min}$ and (weeks 5-12) 3×15 min SSG; $76.5 \%$ of all sessions completed; 84.6\% HRmax.

ST: supervised (weeks 1-4) $2 \times 15$ min SSG, (weeks 5-32) $3 \times 15$ min SSG; $46.2 \%-76.5 \%$ of all sessions completed. weeks 13-52 was $1.5 \mathrm{~min}$. completed. weeks 13-52 was $1.5 \mathrm{~min}$.
As above (see Schmidt et al, 2014), but the rest interval for 2014), but $74.1 \%$ of all sessions added from week 25) and 5 min core training, (months $0-3$ ) ex with 1.5 min rest (months 3-12) 4 sets/ex with 3 min rest, (months 0-1) 16-20 RM, (months 2-12) 8-12 RM; $73 \%$ of all sessions completed. CG: maintain usual lifestyle.

As above (see Schmidt et al, 2014), but the rest interval for

As above (see Schmidt et al, 2014), but the rest interval for CG: maintain daily lifestyle.

As above (see Uth et al, 2014).

As above (see Uth et al, 2014), but 3-7 players a side without reporting training intensity. 
Table 2 Continued

\begin{tabular}{|c|c|c|c|c|}
\hline Author (year) & Design & Intervention programme & Intervention group & Comparison group(s) \\
\hline $\begin{array}{l}\text { de Sousa et } a l^{36} \\
(2014)^{\beta}\end{array}$ & RUT & $\begin{array}{l}12 \text { weeks; (NC) 1/ } \\
\text { week; (NEP) 1/2 } \\
\text { weeks; (SSG) 3/week; } \\
\text { (NEP) } 1 \text { hour; (SSG) } 40 \\
\text { min. }\end{array}$ & $\begin{array}{l}\text { ST: outdoor/indoor; } 3-7 \\
\text { players a side; } 2 \times 12 \text { min } \\
\text { SSG; }>70 \% \text { to }>90 \% \\
\text { HRmax } \\
\text { DI: NC and NEP (cut } 500- \\
1000 \text { kcal/day/subject). }\end{array}$ & $\begin{array}{l}\text { DI: NC and NEP (cut 500-1000 } \\
\text { kcal/day/subject). }\end{array}$ \\
\hline de Sousa et al ${ }^{37}(2017)^{\beta}$ & RUT & $\begin{array}{l}\text { As above (see de Sousa } \\
\text { et al, 2014). }\end{array}$ & $\begin{array}{l}\text { As above (see de Sousa et } \\
\text { al, 2014), but training was } \\
\text { supervised. }\end{array}$ & $\begin{array}{l}\text { As above (see de Sousa et al, } \\
\text { 2014). }\end{array}$ \\
\hline Reddy et $a l^{38}$ & RCT & $\begin{array}{l}12 \text { weeks; 1/week; } 1 \\
\text { hour. }\end{array}$ & $\begin{array}{l}\text { ST: outdoor; } 5 \text { players } \\
\text { a side; walking soccer } \\
\text { games; average } 9.4 \\
\text { sessions completed; } 76 \% \\
\text { HRmax. }\end{array}$ & CG: maintain daily lifestyle. \\
\hline
\end{tabular}

$\alpha, \beta, \gamma, \delta$ : Studies based on the same trial.

As trial results are described in more than one paper, the bolded study represents the first published paper from a given exercise trial. CG, control group; DI, dietary intervention; ex, exercise; HRmax, maximum heart rate; LL, lower limb; NC, nutritional counselling; NEP, Nutritional Education Programme; NRCT, non-randomised controlled trial; RCT, randomised controlled trial; RM, repetition maximum; RT, resistance training; RUT, randomised uncontrolled trial; SSG, small-sided games; ST, soccer training; UL, upper limb.

men and women, while the other three trials reported in ten articles ${ }^{2227-35}$ involved only men (table 1 ). Sample sizes ranged from 20 to 57 subjects, but in three of the five trials, the number of participants randomised was reported differently in the published articles. ${ }^{22}$ 27-32 3637

The age range of participants was from 43 to 75 years. Five articles 2728323435 did not report the age range but only provided the mean and SD or SE. However, in the trial with five papers, ${ }^{22} 29-32$ two ${ }^{22} 30$ reported the participants' age as 65-75 years, two ${ }^{29} 31$ as $63-74$ years, and the remaining one ${ }^{32}$ referred to the articles by Schmidt et $a l^{22}$ and Andersen et $a l^{29}{ }^{29}$ Regarding participant health

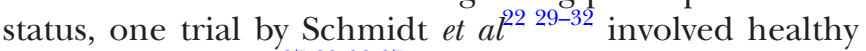
subjects, two trials 27283637 involved patients with type 2 diabetes $(\mathrm{T} 2 \mathrm{D})$, the trial by Uth et $a l^{33-35}$ included men with locally advanced or metastatic prostate cancer (PCa) undergoing androgen deprivation therapy (ADT), and the trial by Reddy and colleagues ${ }^{38}$ did not report health status.

\section{Participant dropouts}

Participants' withdrawal was reported except for the study by Reddy and colleagues, ${ }^{38}$ which apparently had no dropouts. However, the dropout number was reported inconsistently among the other trials and accompanying articles. In the trial by Schmidt et al, ${ }^{27}$ six and nine participants were reported dropping out in weeks 12 and 24, but in the companion paper by Andersen $e t a t^{28}$ there were no dropouts at week 12 and only three dropouts were reported at week 24 . Three articles $^{22} 2931$ from the trial with healthy older men reported that one participant withdrew from the trial, but four and two participants were reported dropping out in the companion papers by Helge et $a l^{30}$ and Sundstrup et $a l l^{32}$ respectively. Two ${ }^{33} 35$ of the three published articles from the trial by Uth and colleagues reported eight and nine participants dropping out. Both articles ${ }^{36} 37$ from the trial by de Sousa and colleagues reported 10 participants withdrawing from the trial, but the dropout rates were $22.7 \%$ and $19.6 \%$, respectively, due to different sample sizes provided.

\section{Interventions}

Of the five trials, ${ }^{22}$ 27-38 three were RCTs, ${ }^{22}{ }^{29-35} 38$ one RUT $^{3637}$ and one NRCT ${ }^{2728}$ (table 2). All the RCTs allocated participants into a soccer training group and a control group, but the RCT with healthy older men ${ }^{22} 29-32$ had an extra comparative treatment group, that is, resistance training. The trial by de Sousa et al with patients with $\mathrm{T}_{2} \mathrm{D}^{36} 37$ randomised participants into soccer+diet group or a diet-only group, while in the NRCT participants formed a training group and a control group.

Intervention period, frequency and session duration

The average duration of the intervention was 28 weeks, with specific reported durations of $12,^{3335-38} 16,,^{29} 24,{ }^{27} 28$ $32^{34}$ and 52 weeks ${ }^{22}$ 30-32. Except for the trial by Reddy et $a l^{38}$ all programmes required participants to exercise two or three times weekly, in which two trials (with six articles) ${ }^{22} 30-3335$ progressed from two to three sessions per week, and one paper ${ }^{34}$ from the PCa trial reported that training commenced with two sessions per week for 8 weeks, increased to three sessions per week for 4 weeks, then decreased to two sessions per week for 20 weeks. In the trial of patients with T2D by de Sousa et $a l^{3637}$ nutritional counselling and nutritional education programme were undertaken once per week and every 2 weeks, respectively. The most common session duration was 60 min. $^{22} 27-3238$ In the PCa trial by Uth et $a l,^{33-35}$ training session duration increased from 45 to $60 \mathrm{~min}$ after week 5 , while $40 \mathrm{~min}$ sessions were undertaken in the trial with patients with T2D. ${ }^{3637}$ 
Table 3 Characteristics of included articles: outcomes

\begin{tabular}{|c|c|c|}
\hline Author (year) & Within-group changes & Between-group changes \\
\hline Schmidt et $a l^{27}(2013)^{\delta}$ & $\begin{array}{l}\text { SBP: STG (12 weeks and } 24 \text { weeks) } \downarrow 5.8 \% \%^{*} \text {; CG } \leftrightarrow \\
\text { DBP: STG (12 weeks) } \downarrow 7.9 \% \%^{*} \text { and ( } 24 \text { weeks) } \\
\downarrow 9.0 \%{ }^{*} \text {; CG } \leftrightarrow \\
\text { VO }: \text { STG (12 weeks) } \uparrow 11.5 \% * \text { and ( } 24 \text { weeks) } \\
\uparrow 11.8 \% \%^{*} ; \text { CG } \leftrightarrow\end{array}$ & $\begin{array}{l}\text { SBPt } \\
\text { DBP† } \\
\text { VO }_{2 \max }(12 \text { weeks and } 24 \text { weeks }) \dagger\end{array}$ \\
\hline Andersen et $a l^{28}(2014)^{\delta}$ & 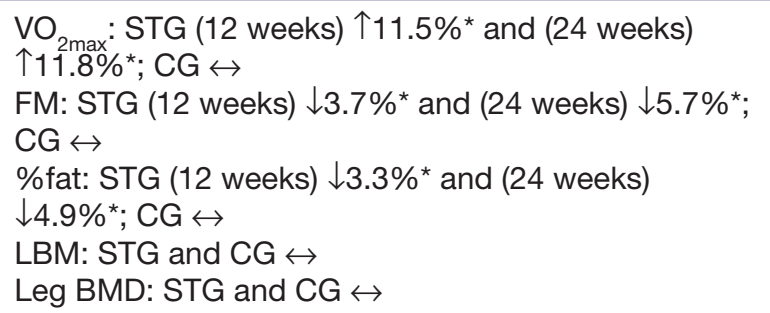 & $\begin{array}{l}\mathrm{VO}_{2 \max }(12 \text { weeks and } 24 \text { weeks }) \dagger \\
\text { FM and \%fat } \dagger \\
\text { LBM: } \leftrightarrow \\
\text { Leg BMD: } \leftrightarrow\end{array}$ \\
\hline Helge et $\left.a\right|^{30}(2014)^{\alpha}$ & $\begin{array}{l}\text { (R)FN BMD: STG (T4) } \leftrightarrow \text { and (T12) } \uparrow 3.7 \% \%^{*}, \uparrow 3.1 \% \S ; \\
\text { RTG and CG } \leftrightarrow \\
\text { (R)TH BMD: STG (T4) } \uparrow 1.0 \% * \text { and (T12) } \uparrow 2.8 \%{ }^{*} \text {, } \\
\uparrow 1.8 \% \S ; \text { RTG and CG } \leftrightarrow \\
\text { TB BMD: STG, RTG and CG } \leftrightarrow\end{array}$ & TB BMD: $\leftrightarrow$ \\
\hline Andersen et $a l^{31}(2016)^{\alpha}$ & $\begin{array}{l}\text { LBM: STG } \leftrightarrow, \text { RTG }(\mathrm{T} 4) \uparrow 2.1 \%{ }^{*} \text { and }(\mathrm{T} 12) \leftrightarrow, \mathrm{CG} \leftrightarrow \\
\text { FM and \% fat: STG, RTG and CG } \leftrightarrow\end{array}$ & $\begin{array}{l}\text { LBM (T4 and T12) } \ddagger \text { (in favour of RTG and } \\
\text { CG) }\end{array}$ \\
\hline Sundstrup et $\left.a\right|^{32}(2016)^{\alpha}$ & 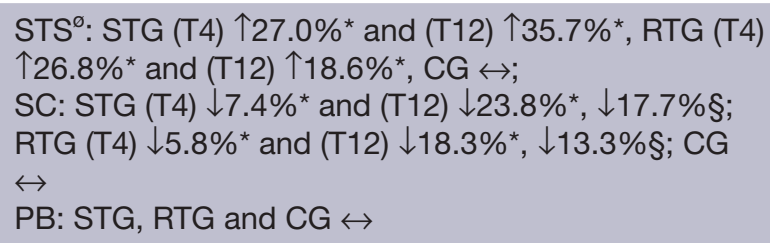 & $\begin{array}{l}\text { STS: STG (T12)† } \\
\text { SC: STG (T12)†; RTG (T12)† }\end{array}$ \\
\hline Uth et $a l^{34}(2016)^{\gamma}$ & $\begin{array}{l}\text { (R)TH BMD: STG } \leftrightarrow ; C G \downarrow 0.8 \% * \\
\text { (R)FN BMD: STG and CG } \leftrightarrow \\
\text { LS BMD: STG and CG } \leftrightarrow \\
\text { LBM: STG and CG } \leftrightarrow \\
\text { FM: STG and CG } \leftrightarrow \\
\text { 1RM: STG } \uparrow 12.5 \% * \text { CG } \uparrow 8.8 \% * \\
\text { STS: STG } \uparrow 10.4 \% * \text { CG } \leftrightarrow \\
\text { SC: STG } \downarrow 7.5 \% * \text { CG } \leftrightarrow \\
\text { PB: STG and CG } \leftrightarrow\end{array}$ & $\begin{array}{l}\text { TH BMD† } \\
\text { FN BMD: } \leftrightarrow \\
\text { LS BMD: } \leftrightarrow \\
\text { LBM: } \leftrightarrow \\
\text { FM: } \leftrightarrow \\
\text { 1RM: } \leftrightarrow \\
\text { STS: } \leftrightarrow \\
\text { SC } \dagger \\
\text { PB: } \leftrightarrow\end{array}$ \\
\hline Uth et $\left.a\right|^{35}(2016)^{\gamma}$ & $\begin{array}{l}\text { TB BMD: STG and CG } \leftrightarrow \text {, legs BMD: STG and CG } \leftrightarrow \\
\text { PB: STG and CG } \leftrightarrow\end{array}$ & $\begin{array}{l}\text { TB BMD: } \leftrightarrow \text {, legs BMD: } \leftrightarrow \\
\text { PB: } \leftrightarrow\end{array}$ \\
\hline de Sousa et $a l^{36}(2014)^{\beta}$ & $\begin{array}{l}\text { VO }{ }_{2 \max }^{\circ}: \text { SDG } \uparrow 10 \%{ }^{*} ; \mathrm{DG} \leftrightarrow \\
\text { FM }^{\circ}: \text { SDG } \downarrow 3.4 \mathbf{~ k g}^{*} ; \text { DG } \downarrow 3.7 \mathrm{~kg}^{*}{ }^{*} \\
\% \text { fat }^{\circ}: \text { SDG and DG } \leftrightarrow \\
\text { LBM: SDG and DG } \leftrightarrow\end{array}$ & $\mathbf{V O}_{2 \max } \ddagger$ \\
\hline de Sousa et al ${ }^{\beta 7}(2017)^{\beta}$ & 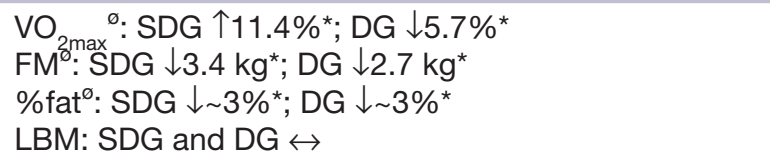 & NR \\
\hline
\end{tabular}


Table 3 Continued

\begin{tabular}{lll}
\hline Author (year) & Within-group changes & Between-group changes \\
\hline Reddy et $\left.a\right|^{38}$ (2017) & SBP/DBP: STG and CG $\leftrightarrow$ & SBP/DBP: $\leftrightarrow$ \\
& \%fat: STG and CG $\leftrightarrow$ & \%fat: $\leftrightarrow$ \\
& PB: STG and CG $\leftrightarrow$ & PB: $\leftrightarrow$ \\
\hline
\end{tabular}

$\alpha, \beta, \gamma, \delta$ : studies based on the same trial; ø: variables reported with inconsistent data among articles from the same trial.

As trial results are described in more than one paper, the bolded study represents the first published paper from a given exercise trial.

*statistically significant from baseline.

†statistically significant from control group.

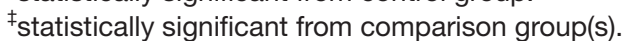

\$statistically significant from 4 months.

$\leftrightarrow$, no change or no difference; $\downarrow$, decrease; $\uparrow$, increase; \%fat, fat percentage; 1RM, 1-repetition maximum; BMD, bone mineral density; CG, control group; DBP, diastolic blood pressure; DG, diet group; FM, fat mass; FN, femoral neck; LBM, lean body mass; LS, lumbar spine; NR, not reported; PB, postural balance; SBP, systolic blood pressure; SC, stair climbing; SDG, soccer+diet group; STG, soccer training group;

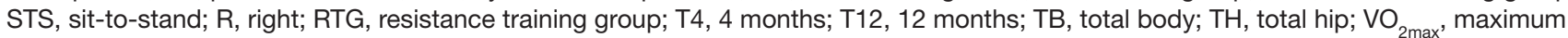
oxygen uptake.

\section{Training volume, intensity and attendance}

The prescribed soccer training volume varied greatly with either progressive or a fixed volume prescribed. In the trial for healthy older men, ${ }^{22} 29-32$ volume progressed from 15 min per game for three games per session for the first 3 months to four games per session in months 3-12, with a 2 min rest interval between games. An incremental training volume was also provided in the trial by $\mathrm{U}$ th $e t$ $a l^{3-35}$ in patients with $\mathrm{PCa}$, which was 15 min per game for two games per session in weeks 1-4 to three games per session in weeks 5-32. An unchanged volume of 10 min per game for five games per session with a $2 \mathrm{~min}$ rest interval between games was prescribed in the trial of men with T2D by Schmidt $e t a l,{ }^{27} 28$ and in the trial by de Sousa and colleagues ${ }^{36}{ }^{37}$ the volume for each training session was $12 \mathrm{~min}$ per game for two games with $3 \mathrm{~min}$ rest between games. In the remaining trial by Reddy et $a l,{ }^{38}$ the volume was not specified.

Although training intensity was not prescribed, session monitoring indicated that the average training intensity was at least $76 \%$ of the maximum heart rate (HRmax), although most studies had an intensity of approximately $80 \%$ and this was reported in nine articles ${ }^{27-30} 323336-38$ that comprised all trials. Of these, six papers ${ }^{27-30} 3233$ from three trials with healthy participants, and patients with T2D and PCa, reported an average training intensity of $>82 \%$ HRmax. All trials reported training attendance rate (ranged from $46.2 \%$ to $77.1 \%$ of prescribed sessions completed), excluding the trial by de Sousa and colleagues ${ }^{36} 37$ in which one article ${ }^{37}$ only reported that 19 of the 22 RS intervention participants completed $100 \%$ of the training sessions.

\section{Game formats}

A variety of soccer game formats were used with three to seven players a side. However, the number of players involved was reported differently among some papers from the same trial. In the article by Schmidt $e t a l^{22}$ in healthy men, games comprised three to five players a side, while the maximum number was six when reported by Andersen $e t a l,{ }^{29}$ and a minimum number of four a side when reported by Andersen $e t a l^{29}$ and Sundstrup $e t$ $a l^{32}$ In addition, the minimum number of players each side was reported as five in the first published paper by Uth $e t a l^{33}$ from the PCa trial, although this was reported as three in one $e^{35}$ of the follow-up articles.

\section{Field of play}

Seven papers ${ }^{22} 31-33$ 35-37 from three trials reported that both an outdoor natural grass pitch and an indoor wooden floor were played on due to alterations in weather conditions. Three articles ${ }^{29} 3038$ that comprised two trials reported playing only on an outdoor surface (natural grass ${ }^{29}{ }^{30}$ or artificial grass pitch ${ }^{38}$ ), although this was reported as both indoor and outdoor in the other papers $^{22} 3132$ from the same trial with healthy older men, and the trial by Schmidt $e t a l^{27} 28$ in patients with T2D reported an indoor wooden court was used. Only one ${ }^{34}$ paper from the PCa trial did not report the field of play, although both outdoor and indoor surfaces were stated in the other two trial papers. ${ }^{335}$ Three trials reported in five papers ${ }^{22} 27283135$ mentioned the size of the field, with $30-45 \mathrm{~m} \times 45-60 \mathrm{~m}$ for the outdoor pitch and $20 \mathrm{~m} \times 40 \mathrm{~m}$ for the indoor court or about $100 \mathrm{~m}^{2}$ per player.

\section{Supervision}

Supervision was provided in two ${ }^{22} 29-35$ of the five trials by either a research staff member ${ }^{22}$ 29-32 or an experienced exercise instructor (exercise physiologist or physiotherapist) ${ }^{33-35}$ In another trial by de Sousa et al reported in two articles, ${ }^{36} 37$ one article ${ }^{37}$ reported that intervention training was supervised, although it did not specify who the supervisor was, while the other article ${ }^{36}$ did not mention supervision.

\section{Outcomes}

A wide array of endpoints were reported in the included $\operatorname{articles}^{2227-38}$; however, due to the focus of the review on health-related benefits, only the most commonly reported variables relating to cardiovascular function, body composition and functional ability were assessed (table 3). 
Cardiovascular function

The $\mathrm{VO}_{2 \max }$ and blood pressure (BP) were the two most commonly evaluated cardiovascular variables. Four trials reported in seven articles ${ }^{22} 27-29333637$ measured $\mathrm{VO}$ using either an incremental cycle ergometer test ${ }^{22} 27-293_{33}$ or treadmill test, ${ }^{3637}$ and all reported a significant improvement between pretest and post-test, in which six ${ }^{22} 27-293637$ quantified the increase as a percentage from $10.0 \%$ to $17.1 \%$, and one ${ }^{33}$ presented it relative to body weight as $1.0 \mathrm{~mL} \mathrm{O}_{2} / \mathrm{kg} / \mathrm{min}(\sim 3.7 \%)$. However, there was some variation in the amount of improvement within the same trial. For example, in the trial of healthy older men, Schmidt $e t a t^{22}$ reported an improvement at 16 weeks of $15.7 \%$, while in the companion paper by Andersen $e t a t^{29}$ it was $13.5 \%$. In a similar fashion, the change in $\mathrm{VO}_{2 \max }$ was reported as $10 \%$ and $11.4 \%$ in the two papers ${ }^{3637}$ from the trial of patients with T2D by de Sousa and colleagues. Of the seven aforementioned articles, two ${ }^{22} 36$ reported a significant difference from the resistance training group ${ }^{22}$ or diet group, ${ }^{36}$ and the trial by Schmidt et al in T2D ${ }^{27} 28$ found a significant change compared with controls. BP was reported in three trials, ${ }^{22} 2738$ in which only one ${ }^{27}$ reported a significant within-group and between-group change.

\section{Body composition}

Lean body mass (LBM) was assessed by dual X-ray absorptiometry (DXA) in four trials and reported in six articles, ${ }^{28} 3133343637$ with only one paper ${ }^{33}$ from the trial of patients with PCa reporting a significant within-group change. Two articles ${ }^{31} 33$ from different trials reported significant between-group changes, but only one ${ }^{33}$ was in favour of the soccer training group.

Seven articles ${ }^{28} 31333436-38$ comprising all trials reported on body fat (four trials that reported fat mass and fat percentage (\%fat) used DXA, ${ }^{28} 3133343637$ and one trial that reported only \%fat used bioelectric impedance ${ }^{38}$ ), in which two articles ${ }^{28} 37$ from different trials in T2D reported a significant decrease from baseline in fat mass and \%fat, and one accompanying paper by de Sousa $e t$ $a l^{36}$ in only fat mass. Interestingly, in the two papers ${ }^{36} 37$ from the trial of patients with T2D by de Sousa et al, one ${ }^{36}$ reported that the reduction of fat mass from baseline was $3.7 \mathrm{~kg}$ in the diet-only group, but the change was $2.7 \mathrm{~kg}$ in the companion paper. ${ }^{37}$

Total body bone mineral density (BMD) assessed by DXA was provided in two trials ${ }^{30} 35$ with no significant changes reported. Femoral neck and total hip BMD results were presented in papers from two trials, ${ }^{30} 34$ of which one ${ }^{30}$ in healthy older men reported a significant difference between baseline and 16 weeks, and the other one ${ }^{34}$ in men with PCa reported a significant difference compared with controls in total hip BMD. Leg BMD was reported in two trials ${ }^{28} 35$ and lumbar spine BMD in one, ${ }^{34}$ but no significant changes were noted.

\section{Functional ability}

Lower limb muscle function and strength were predominantly measured by sit-to-stand (STS), stair climbing (SC) and 1-repetition maximum (1RM). STS results were presented in four articles ${ }^{29}{ }^{32-34}$ from two trials with healthy older men and patients with PCa with a significant improvement from baseline, although the reported change was somewhat inconsistent in two ${ }^{29} 32$ of the companion papers. In addition, two companion articles $^{293}$ in the trial of healthy older men reported a significant difference in STS compared with the control group. SC was reported in two articles ${ }^{32} 34$ from different trials and both reported significant changes from baseline and the control group. 1RM knee extension strength was reported in two ${ }^{33} 34$ papers from the same trial in patients with $\mathrm{PCa}$ with a significant change from baseline, but only one ${ }^{33}$ reported a significant between-group difference. Postural balance was assessed in three trials and reported in four articles ${ }^{32} 343538$ using either the Flamingo test ${ }^{38}$ or SWAY balance test (with such stances as single-leg, bipedal and tandem) $)^{32}$ or both, ${ }^{3435}$ although none reported a significant within-group or betweengroup difference as a result of training.

\section{DISCUSSION}

To our knowledge, this is the first systematic review examining the various health-related effects of RS exclusively in middle-aged and older adults. Based on the current evidence, RS has many potential benefits for middleaged and older adults. Regardless of the substantial heterogeneity among subjects, study designs and intervention programme in the included trials, RS may induce significant changes in cardiovascular function, body composition, lower limb muscle function and strength, although no significant adaptive changes were observed in postural balance.

\section{Cardiovascular adaptations}

Soccer is an intermittent activity involving various intensities of locomotive movements, ranging from walking to high-speed sprints, imposing considerable demands on the cardiovascular system. ${ }^{39}$ Studies suggest that cardiovascular fitness is superior in older soccer players with lifelong soccer participation than for age-matched sedentary individuals ${ }^{40-42}$ and lifelong strength-trained athletes, ${ }^{42}$ and comparable with elderly endurance runners. ${ }^{42}$ It is well established that RS has similar high aerobic demands to elite soccer training. ${ }^{21} 43$ Moreover, several reviews and a meta-analysis indicate that short-term to long-term RS training is similar to interval training and superior to continuous running and strength training in improving $\mathrm{VO}_{2 \max } 16202144$ and $\mathrm{BP}^{162144}$ in untrained, healthy or unhealthy persons.

The results of this review agree with previously conducted reviews mentioned above. In the four trials 22 27-29 333637 that assessed aerobic capacity, $\mathrm{VO}_{2 \max }$ significantly increased $\sim 4 \%-17 \%$ following RS. However, it needs to be noted that not all included trials assessing 
BP reported significant changes following training. Two trials $^{22} 38$ with subjects of either healthy or unknown health status did not report any significant within-group and between-group changes. However, participants in the soccer training groups in these two trials had either normal BP or mild hypertension at baseline. In addition, in the trial of subjects with mild hypertension, ${ }^{38}$ the training stimulus provided of only one session per week for 12 weeks was likely suboptimal to induce a reduction in BP according to the American College of Sports Medicine $^{45}$ and the Exercise and Sports Science Australia ${ }^{46}$ position stands on exercise and hypertension.

\section{Body composition and skeletal health}

$\mathrm{RS}$ is also well documented to be beneficial in inducing positive changes in body composition in various populations. Multiple studies have shown that short-term (12-16 weeks) low-moderate volume RS training is effective in inducing significant changes in total body or regional fat mass, ${ }^{19} 47-52 \%$ fat $^{474850-52}$ and $\mathrm{LBM}^{194753-55}$ in untrained persons.

In contrast, only a few studies have demonstrated beneficial effects on skeletal health after short-term training, and the positive effects were only for lower limb bone mass and markers of bone turnover. ${ }^{18} 19$ These changes likely result from the increased mechanical loading induced by $\mathrm{RS}^{39}{ }^{56}$ However, detecting changes in BMD by DXA following short-term training is unlikely given that the length of the bone remodelling cycle is approximately 4-6 months. ${ }^{57}$ Enhanced bone mass has been reported to be higher in elite female soccer players than in untrained young women ${ }^{58}$ and in untrained women undergoing prolonged RS training. ${ }^{59-61}$

The results from the reviewed trials indicate that RS can be conducive to positive changes in body composition in middle-aged and older adults and especially for those with T2D or PCa undergoing ADT. Of all the papers examining the effects of RS on body composition, ${ }^{28} 303133-38$ three papers ${ }^{28} 3637$ from two separate trials with patients with T2D reported a significant reduction in fat mass and \%fat; one paper ${ }^{33}$ from the trial with PCa survivors reported an increase in LBM similar to that observed with combined resistance and aerobic training $^{62}$; and one article $^{30}$ from the 52-week trial with healthy older adults reported significant improvement in regional BMD.

The mechanisms behind the larger reduction of fat mass in middle-aged and older patients with T2D through RS training could be the enhanced effects resulting from their antidiabetic medications ${ }^{283637}$ or additional dietary intervention ${ }^{36}{ }^{37}$ concurrently received during training. Studies have shown that metformin, the widely used oral antihyperglycaemic agent, ${ }^{63}$ can significantly reduce fat mass and \% fat, ${ }^{64}$ as well as appetite and caloric intake, ${ }^{65}$ in patients with T2D. On the other hand, the greater improvement of LBM in the PCa survivors undergoing $\mathrm{ADT}$ for 1-2 years after a 12-week training programme is probably due to lower baseline values of the participants, given that a substantial loss of muscle mass occurs during the initial period of $\mathrm{ADT}^{6667}$

\section{Functional ability}

Maintaining or enhancing functional ability is essential in older persons in order to maintain independent living. Many factors such as cardiovascular fitness, muscle strength and endurance, and balance can influence functional ability. In addition to the positive adaptations in aerobic capacity, RS as an intermittent sport has particular benefits for anaerobic performance, ${ }^{54} 60$ postural balance, ${ }^{175561}$ lower limb muscular strength ${ }^{5355}$ and function ${ }^{61}$ in young and middle-aged adults, with some changes more significant than continuous running. Similarly, in this review, significant positive adaptations in lower limb muscle function ${ }^{29}{ }^{32-34}$ and strength ${ }^{33} 34$ were observed. But unlike the findings in younger adults, no marked difference was reported in postural balance. ${ }^{32} 343538$

\section{Engagement in RS for middle-aged and older adults}

$\mathrm{RS}$ is reported to be an enjoyable activity that may lead to continued exercise engagement during ${ }^{68-70}$ and even after ${ }^{44}$ participation in a study intervention; however, the highest attendance rate reported in the reviewed articles was $\sim 78 \%$ for a short-term (12 weeks) low-frequency (one session per week) programme. ${ }^{38}$ In the long-term trial of healthy older men, ${ }^{22} 30-32$ even traditional resistance training had a higher attendance rate than RS training ( $73 \%$ vs 66\%). Furthermore, in the 32-week training study on patients with $\mathrm{PCa},{ }^{34}$ only $46 \%$ of the training sessions were completed, which contrasts with the conclusion from a qualitative investigation related to the trial that soccer is a unique strategy contributing to higher physical activity adherence in patients with $\mathrm{PCa}^{71}$ However, reporting of programme compliance was lacking in the trials, which is one of the determinants of the effects derived from an activity programme, as it is possible that a subject may attend a session but not comply with the prescribed intensity or volume. ${ }^{72}$ Therefore, additional work would be beneficial in examining the long-term sustainability of RS in untrained/sedentary middle-aged and older adults, and those with chronic conditions including cancer survivors. In addition, although participation in RS may be safe for middle-aged and older adults, it is still necessary to provide close supervision during the play to prevent potential injury, as the reduction in muscle strength and balance in combination with unfamiliar movements especially in older adults may contribute to falls and subsequent facture.

\section{Limitations}

Since the earliest retrievable RCT by Krustrup et $a l^{19}$ published in 2009, a number of trials have been conducted investigating the health-related effects of RS in untrained subjects, the majority of which involved young adults, adolescents and children, which limited the number of trials available for the current review. Moreover, we found that many articles titled with 'middle-aged' or 
stated investigating the effects of RS in mid-life actually included young adults as participants. $18536073-75$

Within the five separate trials ${ }^{22} 27-38$ included in this review, the sample sizes were generally small, although an extensive array of outcomes were assessed. As a result, there are some potential limitations which are worthy of comment. First, we only presented the most commonly reported variables that may have been assessed with the use of different technologies and procedures. Second, numerous inconsistencies and ambiguities exist among the papers in trial description with regard to participants, the intervention programme and outcomes. Third, a complementary search strategy undertaken to ensure thorough literature searching and avoid missing any relevant literature was to search for well-known authors in the field ${ }^{76}$ although this also has the potential to introduce bias in the selection of papers. However, no additional papers were identified through author searching. Moreover, although major bibliographic searches were undertaken, manual searching of electronic publication lists of key journals and forward citation tracking were not used during the literature search. Fourth, although study eligibility was examined by two independent reviewers and a third reviewer when required, the initial screening of title and abstract was only undertaken by one reviewer. In addition, due to the heterogeneous nature of the included trials, a meta-analysis was not performed. Lastly, the risk of publication bias may exist as only full-text, peer-reviewed journal articles were included, and risk of language bias may also exist as we only included articles published in English.

\section{Future directions}

RS appears to be feasible and beneficial for untrained, healthy or unhealthy middle-aged and older men and women, although robust evidence is lacking. Additional high-quality RCTs are required with focus on study design and reporting of factors related to bias to determine the benefits of RS for different populations especially those with various chronic conditions, as well as in women given that most trials to date have been predominantly in men. In addition, the presence of small or moderate effects of RS training on some health-related endpoints justifies further investigation into the optimal prescription of RS with larger sample sizes and power calculations provided. Finally, additional work is necessary to compare the beneficial effects between RS and other team sport activities (such as touch rugby, netball or basketball) and to develop approaches maintaining higher training adherence in the target populations, especially those with chronic conditions and no prior soccer experience.

\section{CONCLUSION}

RS as sport medicine has potential benefits and should be considered an alternative exercise modality for untrained, healthy or unhealthy middle-aged and older men and women to maintain an active lifestyle and mitigate a wide array of age-related changes in physical and physiological function. However, due to the paucity and variation in quality of available trials, additional highquality RCTs are required to establish more compelling evidence on the positive effects of RS for various populations and especially those with chronic conditions such as cancer, T2D and cardiovascular disease.

Contributors HL, RUN, FM, DAG and DRT contributed to the development of the research question, study design and literature search strategy. $\mathrm{HL}$ conducted the literature search. HL and DRT performed the study selection, methodological quality assessment and data extraction. All authors contributed to data interpretation. HL developed the first draft, and all authors developed the subsequent drafts of the manuscript. All authors reviewed and approved the manuscript.

Funding $\mathrm{HL}$ is funded by the China Scholarship Council (CSC) in conducting collaborative study into sport medicine at Edith Cowan University (ECU) as a visiting scholar. DAG is funded by a Cancer Council Western Australia Research Fellowship.

Competing interests None declared.

Patient consent Not required.

Provenance and peer review Not commissioned; externally peer reviewed.

Open access This is an Open Access article distributed in accordance with the Creative Commons Attribution Non Commercial (CC BY-NC 4.0) license, which permits others to distribute, remix, adapt, build upon this work non-commercially, and license their derivative works on different terms, provided the original work is properly cited and the use is non-commercial. See: http://creativecommons.org/ licenses/by-nc/4.0/

\section{REFERENCES}

1. Young A. Ageing and physiological functions. Phil Trans $R$ Soc $B$ 1997;352:1837-43

2. Dillin A, Gottschling DE, Nyström T. The good and the bad of being connected: the integrons of aging. Curr Opin Cell Biol 2014;26:107-12.

3. White MC, Holman DM, Boehm JE, et al. Age and cancer risk: a potentially modifiable relationship. Am J Prev Med 2014;46(3 Suppl 1):S7-15.

4. Kannel WB, Gordan T. Evaluation of cardiovascular risk in the elderly: the Framingham study. Bull N Y Acad Med 1978;54:573-91.

5. Lloyd-Jones DM, Evans JC, Levy D. Hypertension in adults across the age spectrum: current outcomes and control in the community. JAMA 2005;294:466-72.

6. von Haehling S, Morley JE, Anker SD. An overview of sarcopenia: facts and numbers on prevalence and clinical impact. J Cachexia Sarcopenia Muscle 2010;1:129-33

7. Heaney RP, Abrams S, Dawson-Hughes B, et al. Peak bone mass. Osteoporos Int 2000;11:985-1009.

8. Riggs BL, Khosla S, Melton LJ. Sex steroids and the construction and conservation of the adult skeleton. Endocr Rev 2002;23:279-302.

9. Cheng YJ, Imperatore G, Geiss LS, et al. Secular changes in the age-specific prevalence of diabetes among U.S. adults: 1988-2010. Diabetes Care 2013;36:2690-6.

10. Pedersen BK, Saltin B. Exercise as medicine - evidence for prescribing exercise as therapy in 26 different chronic diseases. Scand J Med Sci Sports 2015;25:1-72.

11. Sparling PB, Howard BJ, Dunstan DW, et al. Recommendations for physical activity in older adults. BMJ 2015;350:h100.

12. Khan KM, Thompson AM, Blair SN, et al. Sport and exercise as contributors to the health of nations. Lancet 2012;380:59-64.

13. Oja P, Titze S, Kokko S, et al. Health benefits of different sport disciplines for adults: systematic review of observational and intervention studies with meta-analysis. Br J Sports Med 2015;49:434-40.

14. FIFA. 2007.FIFA Big Count 2006: 270 million people active in football - FIFA.com https://www.fifa.com/mm/document/fifafacts/ bcoffsurv/bigcount.statspackage_7024.pdf (accessed 19 Oct 2017)

15. Krustrup P, Dvorak J, Junge A, et al. Executive summary: the health and fitness benefits of regular participation in small-sided football games. Scand J Med Sci Sports 2010;20(Suppl 1):132-5.

16. Hammami $A$, Chamari $K$, Slimani $M$, et al. Effects of recreational soccer on physical fitness and health indices in sedentary healthy and unhealthy subjects. Biol Sport 2016;33:127-37. 
17. Jakobsen MD, Sundstrup E, Krustrup P, et al. The effect of recreational soccer training and running on postural balance in untrained men. Eur J Appl Physiol 2011;111:521-30.

18. Mohr M, Helge EW, Petersen LF, et al. Effects of soccer vs swim training on bone formation in sedentary middle-aged women. Eur $\mathrm{J}$ Appl Physiol 2015;115:2671-9.

19. Krustrup P, Nielsen JJ, Krustrup BR, et al. Recreational soccer is an effective health-promoting activity for untrained men. $\mathrm{Br} J$ Sports Med 2009;43:825-31.

20. Milanović Z, Pantelić S, Čović N, et al. Is Recreational Soccer Effective for Improving VO2max A Systematic Review and MetaAnalysis. Sports Med 2015;45:1339-53.

21. Krustrup P, Aagaard P, Nybo L, et al. Recreational football as a health promoting activity: a topical review. Scand J Med Sci Sports 2010;20(Suppl 1):1-13.

22. Schmidt JF, Hansen PR, Andersen TR, et al. Cardiovascular adaptations to 4 and 12 months of football or strength training in 65- to 75-year-old untrained men. Scand J Med Sci Sports 2014;24(Suppl 1):86-97.

23. Moher D, Liberati A, Tetzlaff J, et al. Preferred reporting items for systematic reviews and meta-analyses: the PRISMA statement. $J$ Clin Epidemiol 2009;62:1006-12.

24. Verhagen AP, de Vet HC, de Bie RA, et al. The Delphi list: a criteria list for quality assessment of randomized clinical trials for conducting systematic reviews developed by Delphi consensus. $J$ Clin Epidemiol 1998;51:1235-41.

25. Singh F, Newton RU, Galvão DA, et al. A systematic review of presurgical exercise intervention studies with cancer patients. Surg Oncol 2013;22:92-104.

26. Boutron I, Tubach F, Giraudeau B, et al. Methodological differences in clinical trials evaluating nonpharmacological and pharmacological treatments of hip and knee osteoarthritis. JAMA 2003;290:1062-70.

27. Schmidt JF, Andersen TR, Horton J, et al. Soccer training improves cardiac function in men with type 2 diabetes. Med Sci Sports Exerc 2013;45:2223-33.

28. Andersen TR, Schmidt JF, Thomassen M, et al. A preliminary study: effects of football training on glucose control, body composition, and performance in men with type 2 diabetes. Scand $\mathrm{J} \mathrm{Med} \mathrm{Sci}$ Sports 2014;24(Suppl 1):43-56.

29. Andersen TR, Schmidt JF, Nielsen JJ, et al. Effect of football or strength training on functional ability and physical performance in untrained old men. Scand J Med Sci Sports 2014;24(Suppl 1):76-85.

30. Helge EW, Andersen TR, Schmidt JF, et al. Recreational football improves bone mineral density and bone turnover marker profile in elderly men. Scand J Med Sci Sports 2014;24:98-104.

31. Andersen TR, Schmidt JF, Pedersen MT, et al. The effects of 52 weeks of soccer or resistance training on body composition and muscle function in +65-year-old healthy males--a randomized controlled trial. PLoS One 2016;11:e0148236.

32. Sundstrup E, Jakobsen MD, Andersen LL, et al. Positive effects of 1-year football and strength training on mechanical muscle function and functional capacity in elderly men. Eur J Appl Physiol 2016;116:1127-38

33. Uth J, Hornstrup T, Schmidt JF, et al. Football training improves lean body mass in men with prostate cancer undergoing androgen deprivation therapy. Scand J Med Sci Sports 2014;24:105-12.

34. Uth J, Hornstrup T, Christensen JF, et al. Efficacy of recreational football on bone health, body composition, and physical functioning in men with prostate cancer undergoing androgen deprivation therapy: 32-week follow-up of the FC prostate randomised controlled trial. Osteoporos Int 2016;27:1507-18.

35. Uth J, Hornstrup T, Christensen JF, et al. Football training in men with prostate cancer undergoing androgen deprivation therapy: activity profile and short-term skeletal and postural balance adaptations. Eur J Appl Physiol 2016;116:471-80.

36. de Sousa MV, Fukui R, Krustrup P, et al. Positive effects of footbal on fitness, lipid profile, and insulin resistance in Brazilian patients with type 2 diabetes. Scand J Med Sci Sports 2014;24(Suppl 1):57-65.

37. de Sousa MV, Fukui R, Krustrup P, et al. Combination of recreational soccer and caloric restricted diet reduces markers of protein catabolism and cardiovascular risk in patients with type 2 diabetes. $J$ Nutr Health Aging 2017;21:180-6.

38. Reddy P, Dias I, Holland C, et al. Walking football as sustainable exercise for older adults - A pilot investigation. Eur J Sport Sci 2017;17:638-45.

39. Krustrup P, Helge EW, Hansen PR, et al. Effects of recreational football on women's fitness and health: adaptations and mechanisms. Eur J Appl Physiol 2018;118:11-32.
40. Tessitore A, Meeusen R, Tiberi M, et al. Aerobic and anaerobic profiles, heart rate and match analysis in older soccer players. Ergonomics 2005;48:1365-77.

41. Schmidt JF, Andersen TR, Andersen LJ, et al. Cardiovascular function is better in veteran football players than age-matched untrained elderly healthy men. Scand J Med Sci Sports 2015;25:61-9.

42. Randers MB, Andersen JL, Petersen J, et al. Exercise performance and cardiovascular health variables in 70-year-old male soccer players compared to endurance-trained, strength-trained and untrained age-matched men. J Sports Sci 2014;32:1300-8.

43. Randers MB, Nybo L, Petersen J, et al. Activity profile and physiological response to football training for untrained males and females, elderly and youngsters: influence of the number of players. Scand J Med Sci Sports 2010;20(Suppl 1):14-23.

44. Bangsbo J, Hansen PR, Dvorak J, et al. Recreational football for disease prevention and treatment in untrained men: a narrative review examining cardiovascular health, lipid profile, body composition, muscle strength and functional capacity. $\mathrm{Br} J$ Sports Med 2015;49:568-76.

45. Pescatello LS, Franklin BA, Fagard R, et al. American College of Sports Medicine position stand. Exercise and hypertension. Med Sci Sports Exerc 2004;36:533-53.

46. Sharman JE, Stowasser M. Australian association for exercise and sports science position statement on exercise and hypertension. $J$ Sci Med Sport 2009;12:252-7.

47. Mohr M, Lindenskov A, Holm PM, et al. Football training improves cardiovascular health profile in sedentary, premenopausal hypertensive women. Scand J Med Sci Sports 2014;24(Supp 1):36-42

48. Connolly LJ, Scott S, Mohr M, et al. Effects of small-volume soccer and vibration training on body composition, aerobic fitness, and muscular PCr kinetics for inactive women aged 20-45. J Sport Health Sci 2014;3:284-92.

49. Knoepfli-Lenzin C, Sennhauser C, Toigo M, et al. Effects of a 12week intervention period with football and running for habitually active men with mild hypertension. Scand J Med Sci Sports 2010;20(Suppl 1):72-9.

50. Milanović Z, Pantelić S, Kostić R, et al. Soccer vs. running training effects in young adult men: which programme is more effective in improvement of body composition? Randomized controlled trial. Biol Sport 2015;32:301-5.

51. Arnold JT, Bruce-Low S, Sammut L. The impact of 12 weeks walking football on health and fitness in males over 50 years of age. BMJ Open Sport Exerc Med 2015;1:bmjsem-2015-000048.

52. Barene S, Krustrup P, Jackman SR, et al. Do soccer and Zumba exercise improve fitness and indicators of health among female hospital employees? A 12-week RCT. Scand J Med Sci Sports 2014;24:990-9.

53. Krustrup P, Christensen JF, Randers MB, et al. Muscle adaptations and performance enhancements of soccer training for untrained men. Eur J Appl Physiol 2010;108:1247-58.

54. Bangsbo J, Nielsen JJ, Mohr M, et al. Performance enhancements and muscular adaptations of a 16-week recreational football intervention for untrained women. Scand J Med Sci Sports 2010;20(Suppl 1):24-30.

55. Helge EW, Aagaard P, Jakobsen MD, et al. Recreational football training decreases risk factors for bone fractures in untrained premenopausal women. Scand J Med Sci Sports 2010;20(Suppl 1):31-9.

56. Beck BR, Daly RM, Singh MA, et al. Exercise and Sports Science Australia (ESSA) position statement on exercise prescription for the prevention and management of osteoporosis. J Sci Med Sport 2017;20:438-45

57. Clarke B. Normal bone anatomy and physiology. Clin J Am Soc Nephrol 2008;3(Suppl 3):S131-9.

58. Jackman SR, Scott S, Randers MB, et al. Musculoskeletal health profile for elite female footballers versus untrained young women before and after 16 weeks of football training. J Sports Sci 2013;31:1468-74.

59. Barene S, Krustrup P, Brekke OL, et al. Soccer and Zumba as health-promoting activities among female hospital employees: a 40 -weeks cluster randomised intervention study. J Sports Sci 2014;32:1539-49.

60. Krustrup P, Skoradal MB, Randers MB, et al. Broad-spectrum health improvements with one year of soccer training in inactive mildly hypertensive middle-aged women. Scand J Med Sci Sports 2017;27:1893-901.

61. Krustrup P, Hansen PR, Andersen LJ, et al. Long-term musculoskeletal and cardiac health effects of recreational football and running for premenopausal women. Scand J Med Sci Sports 2010;20:58-71. 
62. Galvão DA, Taaffe DR, Spry N, et al. Combined resistance and aerobic exercise program reverses muscle loss in men undergoing androgen suppression therapy for prostate cancer without bone metastases: a randomized controlled trial. J Clin Oncol 2010;28:340-7.

63. Bailey CJ. Biguanides and NIDDM. Diabetes Care 1992;15:755-72.

64. Aghili R, Malek M, Valojerdi AE, et al. Body composition in adults with newly diagnosed type 2 diabetes: effects of metformin. $J$ Diabetes Metab Disord 2014;13:88.

65. Lee A, Morley JE. Metformin decreases food consumption and induces weight loss in subjects with obesity with type II non-insulindependent diabetes. Obes Res 1998;6:47-53.

66. Galvão DA, Spry NA, Taaffe DR, et al. Changes in muscle, fat and bone mass after 36 weeks of maximal androgen blockade for prostate cancer. BJU Int 2008;102:44-7.

67. Smith MR, Saad F, Egerdie B, et al. Sarcopenia during androgen-deprivation therapy for prostate cancer. $J$ Clin Oncol 2012;30:3271-6.

68. Ottesen L, Jeppesen RS, Krustrup BR. The development of social capital through football and running: studying an intervention program for inactive women. Scand J Med Sci Sports 2010;20 Suppl 1(Suppl 1):118-31.

69. Bruun DM, Bjerre E, Krustrup P, et al. Community-based recreational football: a novel approach to promote physical activity and quality of life in prostate cancer survivors. Int $J$ Environ Res Public Health 2014; $11: 5567-85$
70. Nielsen G, Wikman JM, Jensen CJ, et al. Health promotion: the impact of beliefs of health benefits, social relations and enjoyment on exercise continuation. Scand J Med Sci Sports 2014;24(Suppl 1):66-75.

71. Bruun DM, Krustrup P, Hornstrup T, et al. "All boys and men can play football": a qualitative investigation of recreational football in prostate cancer patients. Scand J Med Sci Sports 2014;24(Suppl 1):113-21.

72. Bolam KA, van Uffelen JG, Taaffe DR. The effect of physical exercise on bone density in middle-aged and older men: a systematic review. Osteoporos Int 2013;24:2749-62.

73. Andersen LJ, Randers MB, Hansen PR, et al. Structural and functional cardiac adaptations to 6 months of football training in untrained hypertensive men. Scand J Med Sci Sports 2014;24:27-35.

74. Krustrup P, Randers MB, Andersen LJ, et al. Soccer improves fitness and attenuates cardiovascular risk factors in hypertensive men. Med Sci Sports Exerc 2013;45:553-61.

75. Andersen LJ, Randers MB, Westh K, et al. Football as a treatment for hypertension in untrained 30-55-year-old men: a prospective randomized study. Scand J Med Sci Sports 2010;20:98-102.

76. Booth A, Papaioannou D, Sutton A. Systematic Approaches to a Successful Literature Review. 78. London: SAGE Publications Ltd, 2012. 